\title{
Structural Mechanical Characteristics and Instability Law of Roof Key Block Breaking in Gob-Side Roadway
}

\author{
Xinfeng Wang $\mathbb{D}^{1,2,3}$ Mingyuan Lu, ${ }^{1}$ Yuhao Gao, ${ }^{1}$ Wenbo Luo, ${ }^{3}$ and Wengang Liu ${ }^{1,2}$ \\ ${ }^{1}$ College of Environment and Resources, Xiangtan University, Xiangtan, Hunan 411105, China \\ ${ }^{2}$ Key Laboratory of Safety and High-Efficiency Coal Mining, Ministry of Education (Anhui University of Science and Technology), \\ Huainan, Anhui 232001, China \\ ${ }^{3}$ Hunan Key Laboratory of Geomechanics and Engineering Safety, College of Civil Engineering and Mechanics, \\ Xiangtan University, Xiangtan, Hunan 411105, China
}

Correspondence should be addressed to Xinfeng Wang; wangxinfeng110@126.com

Received 27 October 2020; Revised 23 November 2020; Accepted 3 December 2020; Published 15 December 2020

Academic Editor: Xiaobo Zhang

Copyright ( 2020 Xinfeng Wang et al. This is an open access article distributed under the Creative Commons Attribution License, which permits unrestricted use, distribution, and reproduction in any medium, provided the original work is properly cited.

\begin{abstract}
The influence of mining on the upper section of working face leads to the fracture of the lateral key block of the roof. From the goaf to the coal body, a group of "left-middle-right" key blocks are formed. According to the three different spatial position structure relations formed by roadway and broken key block in practical engineering, the mechanical causes of broken structure of key block in roof of roadway along goaf are analyzed. FLAC ${ }^{3 \mathrm{D}}$ is used to simulate and analyze the deformation characteristics and stress state of key block structure model before and after roadway excavation, and the mechanical characteristics and instability mechanism of key block sliding and breaking under three spatial structure modes are obtained. With the help of the mathematical model of material mechanics, the structural mechanical behavior of key block model of roof before and after roadway excavation and the temporal and spatial evolution law of unloading and breaking are studied. The results show that the complex influence factors of mining disturbance and low strength of the weak rock mass will weaken the internal balance of "masonry beam" structure. When the roadway is located below the fracture line of the key block, the middle key block will rotate and lose stability with the side hinge joint of the goaf as the axis; when the roadway is located in the fracture line of the key block, it is easy for the middle key block to slide and lose stability; when the roadway is located outside the fracture line of the key block, the middle key block is in the state of complete collapse, the mechanical transmission mechanism of the surrounding rock in the vertical direction is weakened, and the surrounding rock is the most stable.
\end{abstract}

\section{Introduction}

China's energy system is characterized by rich coal, poor oil, and less gas, which determines that coal is still the main energy carrier that supports China's industrial development and economic construction for a long time. With the gradual reduction of mineral resources reserves and the gradual destruction of geological and ecological environment, green mining, precise mining, efficient utilization, and intelligent development have become an important guarantee for coal resources development and sustainable development $[1,2]$. Academician $\mathrm{He}$ and academician Xie have pointed out that there is a strong demand for the development and utilization of deep coal resources under the situation of energy output rising, mining intensity increasing, and mining depth expanding. However, due to the particularity and complexity of deep underground engineering environment, it is still difficult to meet the needs of deep mining to study the deformation and failure mechanism and mechanical evolutionary mechanism of deep rock mass [3-5]. Therefore, it is a direct way and effective measure to solve the problem by vigorously studying the mechanical behavior and dynamic response law of deep rock mass disaster and promoting the new mining system and mining technology.

With the in-depth discussion of Chinese scholars, gobside roadway has become the key research object of efficient mining of coal resources because of its reasonable design method, small amount of roadway excavation, and high coal 
recovery rate. The use of gob-side roadway not only significantly improves the mine production efficiency, but also opens up the direction for the strategic concept of green mining and precise mining in China. However, in view of the complex and diverse mining geological conditions of underground coal and the multifield coupling of "three high and one disturbance" of deep excavation rock mass, how to realize the safety and stability control of gob-side roadway excavation is still facing many challenges.

The problem of asymmetric deformation and failure of roof in the roadway was studied by Xie. The influencing factors of the overall instability of the surrounding rock bearing structure were proposed. The mechanical model of the deep beam structure with strong mining asymmetric anchorage was established, and the stress distribution characteristics of the anchored beam structure and the cooperative bearing machine were analyzed $[6,7]$. Based on the coordinated deformation model, the stability control technology of gob-side roadway retaining in fully mechanized top coal caving face was proposed by using roof presplitting blasting method [8]. Combined with the geological engineering background of fully mechanized top coal caving face, the stress state and failure characteristics of the filling body beside the roadway along goaf were studied by Feng [9]. The structural model of roof fracture of secondary gob-side roadway retaining was established by Kan, and the mechanical evolutionary law and stability control technology of overlying rock deformation and failure of secondary gob-side roadway retaining were revealed [10]. The basic roof of gob-side roadway was divided into three types of fracture by Wang, and the relative difference relationship and evolutionary law of surrounding rock stress and coal pillar pressure were analyzed with the help of numerical software [11]. Through the concrete dynamic analysis of the movement mode of the key block of the "masonry beam" formed by the hard basic roof in the western mining area, the relationship between the extrusion pressure and the inclination angle of key block and the mechanical response characteristics of the key block instability were revealed by Liu [12]. Based on the study of roof breaking law of close distance coal seam group, He has pointed out that the greater the roof damage, the greater the probability of S-R instability. The judgment basis depending on the dynamic variable of collapse pressure and anti extrusion strength attenuation of "masonry beam" hinge point was given [13]. Based on the theory of fracture mechanics, the influence factors of the fracture instability of the cantilever beam were analyzed by Yang. The inclination angle and length of the crack were the key factors causing the fracture and instability of the cantilever beam [14]. Based on the finite difference principle and material failure criterion, the elastic-plastic constitutive model of the primary failure of the basic roof was established by He. The dynamic fracture characteristics of the whole process of the basic roof breaking evolution were analyzed from the aspects of roof breaking position, breaking sequence, and breaking state [15].
The above research provides a generalized model of the broken structure of the key block for the roadway along the goaf, and the mechanical mechanism between the roof of the "masonry beam" structure and the coal mass in the goaf below, the instability process, and the determination method of the key block are given. However, the space-time relationship and mechanical response mechanism of roadway along goaf and upper key block have not been systematically integrated. Based on the theory of "masonry beam" key block, this paper focuses on three kinds of spatial relationship between gob-side roadway and upper layer key block breaking: roadway is located under the fracture line of key block, roadway is located inside the fracture line of key block, and roadway is located outside the fracture line of key block. The structural model of roof key block fracture is established, and the mechanical causes of key block fracture structure are analyzed. Through three-dimensional numerical simulation and theoretical analysis, the mechanical mechanism and deformation law of roof key blocks are revealed under three kinds of spatial structure states, and the judgment basis for the optimal selection of space-time position of gob-side roadway and upper broken key block and disaster prevention and control is provided.

\section{Analysis of Spatial Structure Model of Roof Key Block Breaking in Gob-Side Roadway}

During the mining process of coal body in the upper section working face, the coal edge supporting the basic roof in the direction of side goaf changes from elastic state to plastic failure state, resulting in a large amount of bending deformation [16]. With the continuous influence of dynamic pressure and the continuous advance of the working face, the overlying strata structure is destroyed, forming a group of three key blocks, namely, the right key block, the middle key block, and the left key block. The spatial structure model is shown in Figure 1.

The direct roof of the upper working face gradually collapses with the mining of the lower coal body, and the basic roof breaks at the bearing fulcrum of both ends of the rock beam. The right key block is completely compacted on the gangue pile of the upper section working face and forms an articulated relationship with the adjacent fractured rock beams [16]. The stress analysis of the middle key block is shown in Figure 2; the middle key block is squeezed with adjacent rock beam under the action of left and right horizontal extrusion force $T$, and the shear forces $Q_{A}$ and $Q_{C}$ on the contact angle make it stable in the vertical direction. Taking the left hinge joint as the axis, it rotates and sinks to the right goaf direction, showing a stepped subsidence structure.

In Figure $2, T_{a}$ and $T_{c}$ are the squeezing forces of adjacent rock beams, $\mathrm{kN} ; G_{b}$ is the self-weight stress, $\mathrm{kN} ; q_{1}$ is the supporting load of coal body and direct roof, $\mathrm{kN} / \mathrm{m} ; q_{0}$ is the overburden load, $\mathrm{kN} / \mathrm{m} ; Q_{A}$ and $Q_{C}$ are the shear forces of rock beam, $\mathrm{kN} ; l_{1}$ is the supporting load length, $m ; l_{0}$ is the rock block length, $m ; h_{0}$ is the depth of stratum, $m$; and $\theta$ is the middle key block angle. 


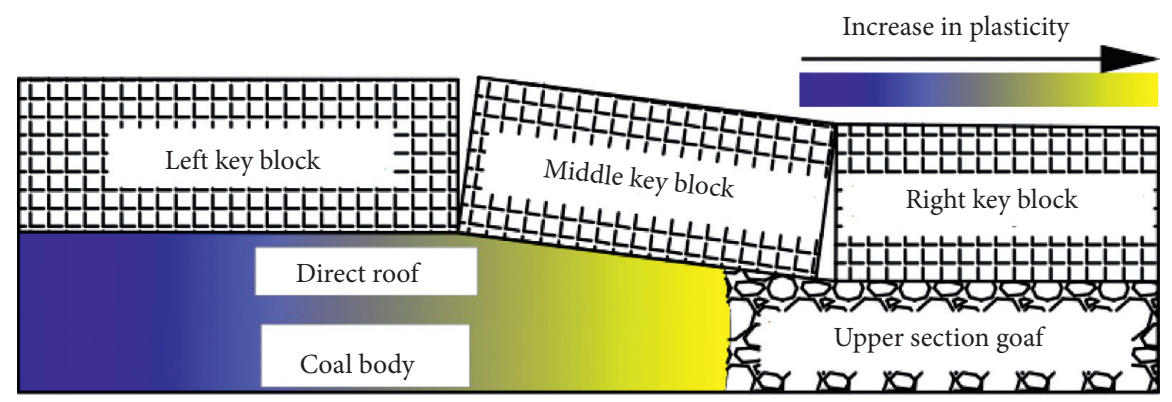

FIGURE 1: Schematic diagram of key block fracture structure model.

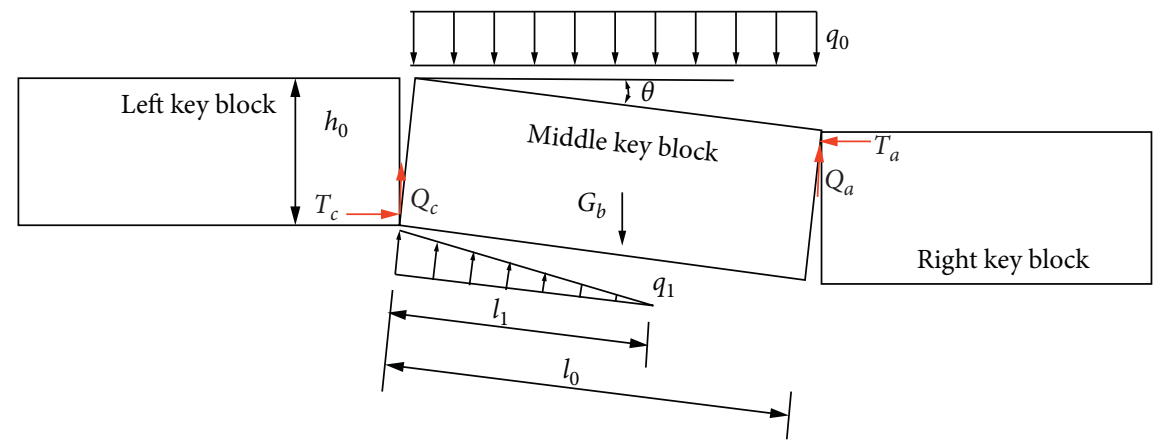

Figure 2: Stress analysis of the middle key block.

\section{Mechanical Cause Analysis of Space Structure Broken by Key Blocks}

Based on the analysis of key stratum theory, a large amount of coal mining results in a large area of goaf, which is accompanied by "three zones" of roof. Because the soft cushion held by the key layers of each layer will weaken the mechanical transmission capacity of the overlying strata in the vertical direction, the multiple groups of "masonry beam" structure formed in the vertical direction of the fracture zone will also play a certain supporting role on the underlying rock layer, which makes it difficult for the mechanical response mechanism of the lowest basic roof to show an obvious upward trend with the increase of the working face buried depth. Therefore, the movement structure of the lowest sub-key layer of the key block is not affected by the migration of overlying strata, but only determined by its own mechanical characteristics and rock properties, and its movement characteristics will play a key role in restricting the direct roof below and the pressure bearing state of the coal body.

The condition of the key block rotating instability is that the extrusion force at the hinge point is greater than the anti extrusion strength; that is, the hinge joint strength of the key block cannot support the transmission force of adjacent rock beams $[17,18]$; the expression is

$$
T>a \cdot \eta \cdot \sigma_{c} .
$$

In (1), $a$ is contact area of hinge point, $\mathrm{m}^{2} ; \eta$ is extrusion strength coefficient of contact surface; and $\sigma_{c}$ is extrusion strength of contact surface, MPa.

$$
h+h_{1} \leq \frac{0.15 \sigma_{c}}{\rho g}\left(i^{2}-\frac{2}{3} i \cdot \sin \theta+\sin ^{2} \theta\right) .
$$

In (2), $h$ is thickness of coal seam, $m ; h_{1}$ is thickness of immediate roof, $m ; \sigma_{c}$ is extrusion strength, $\mathrm{MPa} ; i$ is rock mass fragmentation; $\theta$ is dip angle; $\rho$ is rock mass density, $\mathrm{kg} /$ $\mathrm{m}^{3}$; and $\mathrm{g}$ is acceleration of gravity, $\mathrm{N} / \mathrm{kg}$.

When the right key block in the upper section gradually sinks, it will drive the middle key block to rotate towards the goaf and fracture. Before the two key blocks reach the initial balance, the rotation angle of the middle key block increases gradually, and the fracture boundary on both sides is rotated to form hinge joint.

For the hard roof rock mass of shallow deep mine, when the antiextrusion strength of the hinge point is greater than the horizontal extrusion pressure, a stable key block structure of "masonry beam" is formed. Even if the roadway along the goaf is excavated in the lower coal body, the hinge point can still maintain a relatively stable self-balance state without breaking. However, in the deep soft rock roadway, the hinge point is often in the postfailure stage. The main reasons for the fracture of the hinge point are as follows: On the one hand, the coal seam group composed of multilayer coal body is distributed from the top to the bottom of the deep mine. The basic roof of this coal seam is located in the influence area of the floor damage when the upper coal mining disturbance occurs, the integrity of the upper part of the basic roof and even the whole rock beam is damaged, and the bearing capacity and stability are greatly reduced [13]. On the other hand, the roof rock layer in the "three soft" coal seam in deep mine is relatively soft, and the compressive strength of rock mass is greatly reduced, which makes the 
judgment conditions of rotary deformation and instability of surrounding rock reduced. It is difficult for the "masonry beam" to form a stable hinge point, and the rock movement continuously causes subsidence and is gradually compacted on the supporting body below. The supporting load provided by the support body increases gradually, which causes the key block to evolve from the rotary instability to the limit equilibrium state, until the overburden structure is balanced again.

In the limit equilibrium state of the deep soft rock roof, the mechanical properties and integrity of the rock at the hinge joints on both sides are poor, so it is difficult to provide enough shear force and extrusion force. Therefore, the coal body and direct roof under the middle key block are the main supporting loads to maintain the structural stability. When the roadway is excavated under the basic roof, the redistribution of coal stress will seriously affect the supporting force of overlying strata, break the limit equilibrium state, and lead to S-R instability of the key broken block. The load generated by the "given deformation" state will directly act on the surrounding rock of the roadway until a new equilibrium is reached.

\section{Analysis of Breaking and Instability Characteristics of Key Roof Blocks in Gob- Side Roadway Based on Numerical Simulation}

4.1. Establishment of Numerical Model. After the excavation of underground coal and rock mass, the roof of gob-side roadway is damaged, which leads to the deformation and fracture of the upper key block. The spatial position relationship between gob-side roadway and key block can be divided into three types: the roadway is located under the fracture line of the key block, the roadway is located inside the fracture line of the key block, and the roadway is located outside the fracture line of the key block [11]. The stressstrain characteristics of surrounding rock caused by three kinds of roadway layout are analyzed using FLAC $^{3 \mathrm{D}} \mathrm{nu}-$ merical simulation software, and the spatiotemporal evolution process of key block failure is explored.

The model size is divided into $150 \mathrm{~m} \times 30 \mathrm{~m} \times 50 \mathrm{~m}$, and the three-dimensional numerical analysis model as shown in Figure 3 is established. The displacement constraint boundary is set on the left and right sides of the model, the bottom of the model is fixed as the full constraint boundary, the corresponding displacement constraint boundary is set at the top of the model synchronously, and the vertical uniform load is applied above the model. The model is divided into five groups of strata from bottom to top, which represent basic floor, immediate floor, coal body, immediate roof, and basic roof. The basic roof is divided into three groups every $50 \mathrm{~m}$ along the $x$-axis direction, including the left key block, the middle key block, and the right key block. The Mohr-Coulomb constitutive yield criterion is used to reveal the evolutionary process of dynamic failure of surrounding rock. The rock mechanical parameters selected by simulation are shown in Table 1.
This model mainly highlights the manifestation of the force exerted on the roadway surrounding rock by the breaking key block, so it simplifies the basic overlying strata model. An in situ stress load of $20 \mathrm{MPa}$ was applied in the area with a height of $50 \mathrm{~m}$. In the right side of the model, the null model is established to simulate the goaf, and large deformation is used to simulate the caving characteristics of roof strata. The interface between the left key block, the middle key block, and the right key block is established to simulate the crack and hinge joint of the "masonry beam" structure. After calculating the balance of the goaf model, the $4 \mathrm{~m} \times 3 \mathrm{~m}$ gob-side roadway is excavated according to the space position of the roadway and the key block fracture line, as shown in roadway (1), roadway (2), and roadway (3) in Figure 3. Meanwhile, the $4 \mathrm{~m}$ narrow coal pillar is reserved for roadway protection.

\subsection{Stress Distribution Characteristics of Key Block Fracture.} The vertical stresses of overburden space structure before and after excavation of three kinds of gob-side roadways are analyzed, which are located under the fracture line of the key block, inside the fault line of the key block, and outside the fault line of the key block. The stress evolutionary nephogram is shown in Figures 4-6.

Before roadway excavation, the middle key block, the left key block, and the right key block jointly form the stepped sinking structure of "masonry beam." The key blocks of model (1) and model (2) belong to oblique overlapping state, while the key blocks of model (3) are in horizontal compaction state. The influence range of supporting pressure on coal wall side is smaller and more stable than the former two models.

After the roadway excavation, the maximum vertical support pressure of coal pillar is about $35 \mathrm{MPa}$ when it is directly below the fracture line of key block, The value is about $31 \mathrm{MPa}$ when it is located inside the fracture line of the key block, and the minimum value is about $13 \mathrm{MPa}$ when it is far away from the action range of the key block. With the different space position of roadway layout, the support pressure of coal pillar decreases obviously. It can be seen that the spatial position relationship between the middle key block and the gob-side roadway is the key factor affecting the surrounding rock stability of gob-side roadway. When the roadway is located at any position below the key block, it will show different stress characteristics. The deformation of surrounding rock is the macroscopic manifestation of the corresponding supporting pressure caused by different shapes of the middle key block.

The right part of the middle key block of model (1) is compacted on the gangue pile in the goaf, and the plastic stress increases. The supporting load on the left end point is completely borne by the coal pillar. The large span and inclination angle produced by the oblique overlapping state of the middle key block lead to the obvious stress concentration phenomenon in the left bottom corner and right top corner of the coal pillar, for which it is easy to cause the single inclined plane shear failure of the coal pillar. In addition, the left hinge joint plays a role of mechanical 


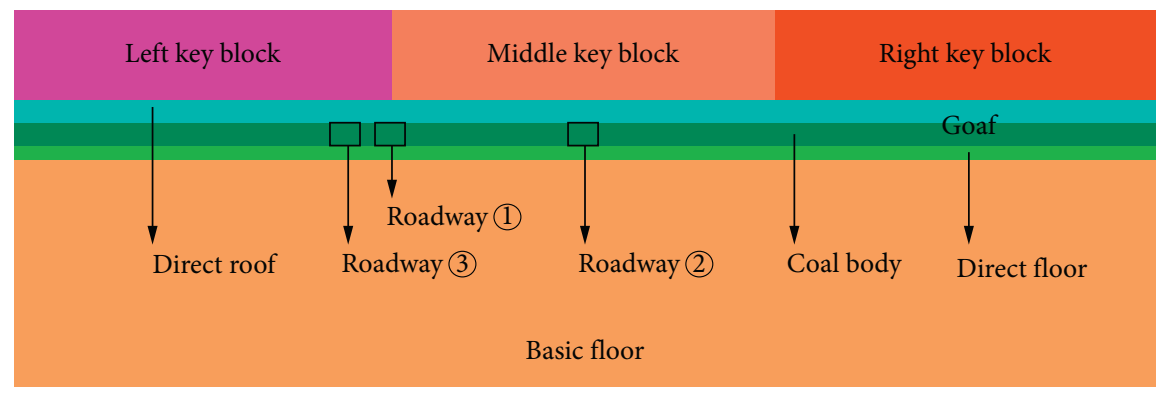

FIGURE 3: Numerical analysis model.

TABle 1: Parameters of rock mechanics.

\begin{tabular}{lccccc}
\hline Classification & $B(\mathrm{GPa})$ & $S(\mathrm{GPa})$ & $C(\mathrm{MPa})$ & $f\left(^{\circ}\right)$ & $T(\mathrm{MPa})$ \\
\hline Right key block & 5.65 & 5.25 & 8.0 & 30.5 & 7.6 \\
Middle key block & 5.65 & 5.25 & 8.0 & 30.5 & 7.6 \\
Left key block & 5.65 & 5.25 & 8.0 & 30.5 & 7.6 \\
Immediate roof & 0.65 & 0.62 & 6.0 & 25.6 & 5.4 \\
Coal body & 0.25 & 0.62 & 6.0 & 30.0 & 2.0 \\
Immediate floor & 0.53 & 0.41 & 6.0 & 25.6 & 5.3 \\
Basic floor & 4.80 & 4.60 & 5.0 & 20.0 & 6.0 \\
\hline
\end{tabular}

transmission in the process of roadway excavation, which drives the left coal mass to produce a large range of stress increasing area and causes the roof subsidence and bottom heave. When the mining disturbance scope of the working face gradually expands, there is a hidden danger of S-R instability in the middle key block, which will lead to a large amount of direct roof caving and single inclined plane shear failure of coal pillar.

The left side of the middle key block of model (2) is located on the solid coal, bearing the maximum supporting load, and the right side is mainly balanced by the extrusion friction of hinge joint, forming a relatively stable triangular support structure, which plays a certain supporting role for roadway excavation. As the supporting point of the upper rock beam, the coal pillar guides the support pressure to transfer to the deep coal body, resulting in a large range of stress increasing area at the coal wall side of the roadway. Because the coal pillar is located directly below the middle key block, the stress increase area in the middle of the coal pillar will be generated due to the splitting effect, which aggravates the risk of "left bottom corner middle right top corner" breakthrough failure of coal pillar. At the same time, because the whole roadway is enveloped by the middle key block and the stress increasing area under the two sides is connected at the floor, the superimposed pressure will have a strong impact on the floor. Therefore, for this kind of space structure roadway, attention should be paid to the floor pressure relief and support measures to alleviate the damage of superimposed pressure.

In model (3), when the goaf is formed, there is no supporting load under the hinge joint on the left side of the broken roof, so it is difficult to support the inclined overlapping stable structure depending on the shear force at the hinge point, so as to completely lose the stability and make it compacted on the gangue pile in the goaf to produce plastic stress peak value. For the coal body, the force is only the reverse force produced by the left key block when resisting the sliding instability of the broken roof, and when the hinge joint is completely destroyed, the reverse force will disappear. Therefore, the surrounding rock stress of the roadway is the minimum, the displacement is also the minimum, and the surrounding rock state is the most stable. However, such key blocks will cause severe roof disturbance when roof cutting occurs, accompanied by obvious energy release and abnormal ground pressure. Therefore, special attention should be paid to the safety of personnel and equipment near the working face at that time.

4.3. Deformation Instability Characteristics of Key Block Fracture. Through dynamic observation and analysis of the surrounding rock displacement changes of the three roadway models after excavation, the displacement evolution nephogram is obtained, as shown in Figure 7. After the excavation of roadway, the plastic failure characteristics of coal pillar radial expansion and axial compression are obvious. The surrounding rock of roadway generally presents the deformation evolution characteristics of concave corner, convex side line, from square to $X$ shape. Due to the oblique eccentric load action of the middle key block of model (1) and model (2) and the left horizontal thrust action of the middle key block of model (3), the surrounding rock of roadway presents the evolution trend of oblique deformation, and the deformation amount decreases gradually.

The displacement curve is drawn with the maximum unbalanced force operation sequence in FLAC ${ }^{3 \mathrm{D}}$ simulation as abscissa and the displacement of two sides of roadway, roof, and floor as ordinate, as shown in Figure 8.

According to the analysis in Figure 8, the displacement curves of coal wall side of roadway (1) and roadway (2) are approximately equal, which is consistent with the phenomenon of coal wall side support pressure shown in Figures 4 and 5. The displacement of side and roof of coal pillar shows corresponding numerical changes due to different supporting pressure. The floor heave curve of roadway (2) is slightly higher than that of roadway (1). Compared with the stress distribution nephogram in Figures 4 and 5, it can be seen that the floor pressure stress areas of roadway (1) are, respectively, limited under the coal wall and coal pillar, and the floor pressure stress areas of two sides of roadway (2) have a penetrating and overlapping effect, which causes the 


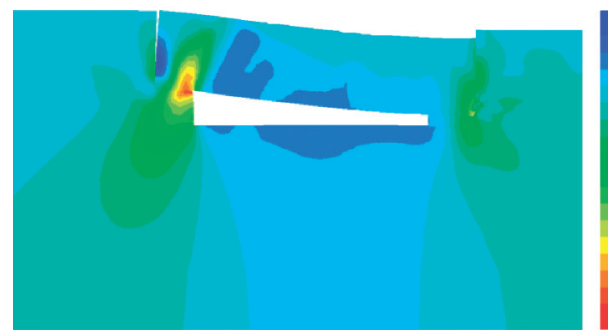

(a)

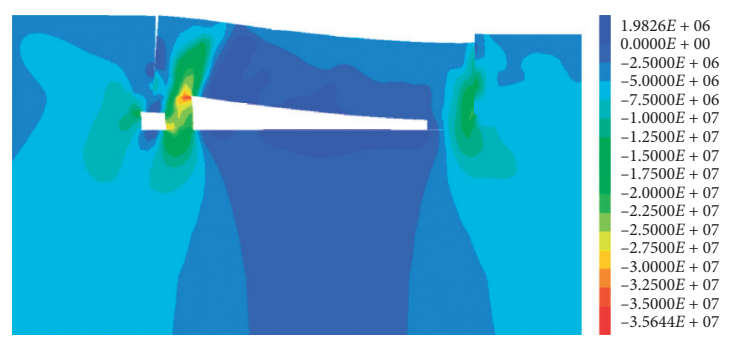

(b)

FIgURE 4: Vertical stress distribution map of overburden structure before and after excavation when roadway is under the fracture line of key block. (a) Before roadway excavation (unit: Pa). (b) After roadway excavation (unit: Pa).

floor heave to increase. Comprehensive analysis of the deformation displacement curve of surrounding rock at different positions of the roadway shows that the displacement of surrounding rock of roadway (3) is the smallest, and no obvious deformation occurs on the whole.

\section{Mechanical Evolutionary Law of Roof Key Block Breaking in Gob-Side Roadway}

5.1. Mechanical Model Analysis of Key Block Structure before Roadway Excavation. Based on the above-mentioned structural characteristics of "masonry beam," the mechanical model of the key block in the roof of gob-side entry is constructed. Considering that the thickness of overlying strata in deep mine working face is relatively large, usually more than $800 \mathrm{~m}$, the difference of overburden load caused by rotation subsidence of key block can be ignored, and the force exerted by overlying strata on the key block is approximately uniform load in vertical direction. With the rotation and subsidence of the key block in the middle position, the collapsed rock layer is gradually compacted on the direct roof and coal body below, resulting in the increasing of the supporting force of coal and rock mass, and the bearing structure gradually reaches the limit equilibrium state. The direct roof and coal body change from original rock state to goaf from elastic deformation to plastic yield until plastic failure. The supporting effect of surrounding rock on the key block is nonuniform load, which shows a linear decreasing trend approximately.

The stress model of the key block in Figure 2 is improved to the "masonry beam" optimization model as shown in Figure 9, and then the stress status of the key block is analyzed. In Figure 9, the shear force and compression force on both sides evolve into four hinge bearings, which are omitted because the self-weight is smaller than the load of overlying strata. This model is a one-time statically indeterminate model; the model is further refined and decomposed to form the radial force model of "masonry beam" shown in Figure 10 and the axial force model of "masonry beam" shown in Figure 11. Then, the improved radial force model of masonry beam and the axial force model of masonry beam are solved, respectively, and the radial force $F_{A Y}, F_{C Y}$ and axial force $F_{A X}, F_{C X}$ of rock beam model are obtained.

The radial force model of "masonry beam" in Figure 10 is analyzed, and the equilibrium condition is obtained.

$$
\left\{\begin{array}{l}
\sum F_{X}=0 \Rightarrow F_{C X}+\int_{0}^{l_{0}} q_{0} \sin \theta \mathrm{d} x=F_{A X} \\
\Rightarrow F_{C X}+q_{0} l_{0} \sin \theta=F_{A X}, \\
\sum F_{Y}=0 \Rightarrow F_{C Y}+F_{A Y}+\frac{1}{2} q_{1} l_{1}=q_{0} l_{0} \cos \theta \\
\Rightarrow F_{C Y}+F_{A Y}=q_{0} l_{0} \cos \theta-\frac{1}{2} q_{1} l_{1}, \\
\sum M_{O}=0 \Rightarrow q_{0} l_{0} \cos \theta \cdot \frac{1}{2} l_{0} \cos \theta \\
=F_{A Y} l_{0}+\int_{0}^{l_{1}}\left(q_{1}-\frac{q_{1}}{l_{1}} x\right) x \mathrm{~d} x=F_{A Y} l_{0}+\frac{1}{6} q_{1} l_{1}^{2} .
\end{array}\right.
$$

After solving, the results are as follows:

$$
\left\{\begin{array}{l}
F_{A Y}=\frac{1}{2} \cos ^{2} \theta q_{0} l_{0}-\frac{1}{6} q_{1} \frac{l_{1}^{2}}{l_{0}}, \\
F_{C Y}=q_{0} l_{0} \cos \theta\left(1-\frac{1}{2} \cos \theta\right)-\frac{1}{2} q_{1} l_{1}\left(1-\frac{1}{3} \frac{l_{1}}{l_{0}}\right) .
\end{array}\right.
$$

In (3) and (4), $F_{X}$ is the force characteristic in $X$ direction, $\mathrm{kN} ; F_{Y}$ is the force characteristic in $Y$ direction, $\mathrm{kN} ; M_{0}$ is the moment at the hinge point $O$ between the middle key block and the left key block, $\mathrm{kN} \cdot \mathrm{m} ; F_{C X}$ is the axial force of the left key block along the middle key block, $\mathrm{kN} ; l_{0}$ is the rock block length, $m ; q_{0}$ is the overburden load, $\mathrm{kN} / \mathrm{m} ; F_{A X}$ is the axial force of the right key block along the middle key block, $\mathrm{kN} ; \theta$ is the inclination angle of beam; $F_{C Y}$ is the radial force at the hinge joint between the middle key block and the left key block, $\mathrm{kN} ; F_{A Y}$ is the radial force at the hinge joint between the middle key block and the right key block, $\mathrm{kN}$; $q_{1}$ is the supporting load provided by the direct roof and coal body below, $\mathrm{kN} / \mathrm{m}$; and $l_{1}$ is the length of direct roof and coal body below, $m$.

The axial force model of "masonry beam" structure in Figure 11 is analyzed, and the equilibrium condition is obtained. 


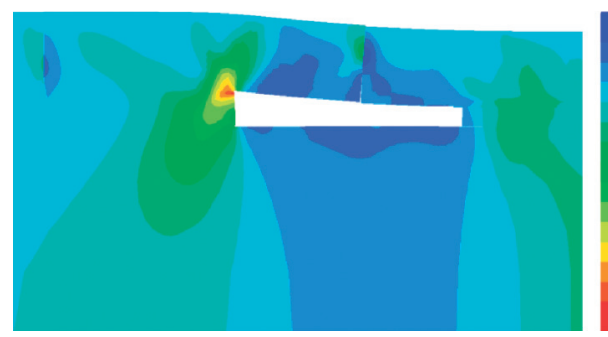

(a)

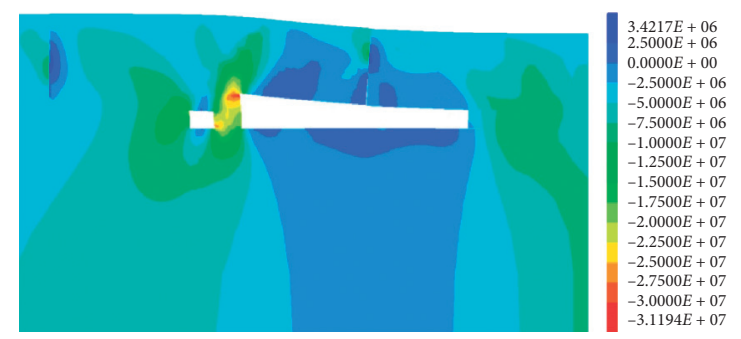

(b)

FIGURE 5: Vertical stress distribution map of overburden structure before and after excavation when roadway is located in the fracture line of key block. (a) Before roadway excavation (unit: Pa). (b) After roadway excavation (unit: Pa).

$$
\left\{\begin{array}{l}
F_{C X}+q_{0} \sin \theta x+F_{N}(x)=0, \\
\varepsilon(x)=\frac{\sigma}{E}=\frac{F_{N}(x)}{E A}=-\frac{F_{C X}}{E A}-\frac{q_{0} \sin \theta x}{E A}, \\
\Delta L(x)=\int_{0}^{x} \varepsilon(x) \mathrm{d} x=-\frac{F_{C X}}{E A} x-\frac{q_{0} \sin \theta}{E A} \frac{x^{2}}{2} .
\end{array}\right.
$$

When $x$ is equal to the total length of $l_{0}$, we get

$$
\Delta L\left(l_{0}\right)=-\frac{F_{C X}}{E A} l_{0}-\frac{q_{0} \sin \theta}{E A} \frac{l_{0}^{2}}{2}=0 .
$$

After further solution,

$$
\left\{\begin{array}{l}
F_{C X}=-\frac{1}{2} q_{0} l_{0} \sin \theta, \\
F_{A X}=-\frac{1}{2} q_{0} l_{0} \sin \theta+q_{0} l_{0} \sin \theta=\frac{1}{2} q_{0} l_{0} \sin \theta .
\end{array}\right.
$$

In (5)-(7), $x$ is the axial length variable of the beam, $m$; $F_{N}(x)$ is the axial force function about $x ; \varepsilon(x)=(\sigma / E)$ is a function of Hooke's law about $x$; $\mathrm{E}$ is the elastic modulus, $\mathrm{Pa}$; $A$ is the cross-sectional area of the bar, $\mathrm{m}^{2}$; and $\Delta L(x)$ is the elongation function about $x$.

The definition of radial force $F_{A Y}, F_{C Y}$ and axial force $F_{A X}, F_{C X}$ in the material mechanics model is the hinge support reaction force to maintain the stability of the structure. In practical engineering problems, they are the mechanical framework of the coupling of extrusion force $T$ and shear force $Q$, as shown in

$$
\begin{aligned}
& \left\{\begin{array}{l}
F_{A Y}=Q_{A}+T_{A} \sin \theta, \\
F_{C Y}=Q_{C}+T_{C} \sin \theta,
\end{array}\right. \\
& \left\{\begin{array}{l}
F_{A X}=T_{A} \cos \theta, \\
F_{C X}=T_{C} \cos \theta .
\end{array}\right.
\end{aligned}
$$

The shear force $Q$ is nominally generated by the friction resistance of axial force $F_{X}$ at the hinge point, but it is not equal in the field measurement value, which means that the shear force $Q$ is affected by many factors such as the strength of the contact surface at the hinge point, rock properties, and hydrogeological conditions.
According to the mathematical analysis, when the middle key block reaches the limit equilibrium state, the mechanical properties of the rock at the hinge point are poor, and the friction mechanical connection between the shear stress and the extrusion force is weak, which can be regarded as separate force. In the same underground engineering environment, when the limit equilibrium state is destroyed due to mining disturbance, according to (4) and (8), the shear force $Q_{A}, Q_{C}$ at the hinge point of the middle key block is mainly affected by the support load $q_{1}$ and the inclination angle $\theta$. According to (7) and (9), extrusion forces $T_{C}$ and $T_{A}$ are only affected by inclination angle $\theta$. In practical engineering, the cause of structural instability is usually the excavation of gob-side roadway, which directly leads to the decrease of support load $q_{1}$ and the redistribution of stress state of the middle key block. With the gradual decrease of support load $q_{1}$, the shear force $Q_{A}$ and $Q_{C}$ will increase, and the increase range of $Q_{C}$ is greater than that of $Q_{A}$. However, due to the weak nature of rock, the shear force provided by it is far less than the shrinkage of support load $q_{1}$ amplitude reduction. Therefore, the middle key block rotates to the horizontal direction, the inclination angle $\theta$ decreases, the extrusion pressures $T_{C}$ and $T_{A}$ produce synchronous attenuation, and the key block breaking shows a sinking trend, for which it is easy to cause instability.

\subsection{Evolution Law of Key Block Breaking and Instability after} Roadway Excavation. Tunnel excavation leads to stress unloading of surrounding rock, resulting in secondary distribution of initial equilibrium stress field. With shear dilatancy failure of internal weak structural plane, surrounding rock quickly presents yield state and gradually loses bearing capacity [19], which leads to secondary subsidence of broken key block. The migration and subsidence trend of key broken block after three groups of model roadway excavation is shown in Figure 12.

According to the previous calculation formula of mine stress and strata control theory [20], the width of limit equilibrium zone of roadway side is

$$
x_{0}=\frac{m A}{2 \operatorname{tg} \varphi_{0}} \ln \left(\frac{k \gamma H+\left(C_{0} / \operatorname{tg} \varphi_{0}\right)}{\left(C_{0} / \operatorname{tg} \varphi_{0}\right)+\left(P_{x} / A\right)}\right) .
$$

In (10), $m$ is the mining thickness of coal seam, $m$; $A$ is the side pressure coefficient; $\operatorname{tg} \varphi$ is the friction coefficient; $k$ is 


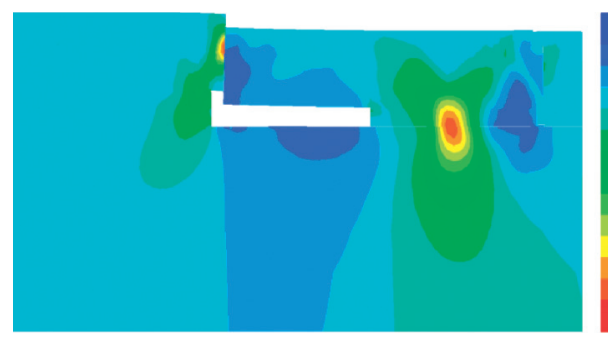

(a)

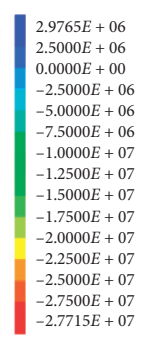

$7500 E+07$

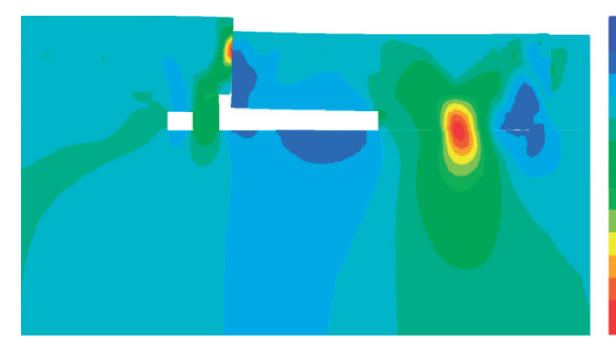

(b)

FIGURE 6: Vertical stress distribution map of overburden structure before and after excavation when roadway is located outside the fracture line of key block. (a) Before roadway excavation (unit: Pa). (b) After roadway excavation (unit: Pa).

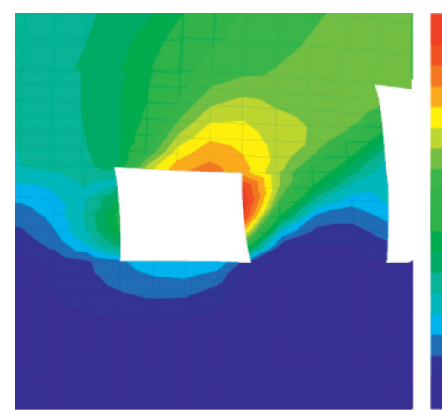

(a)

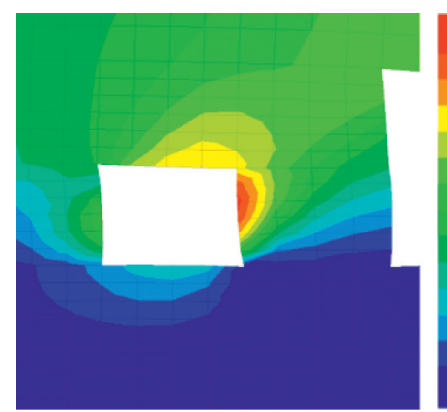

(b)

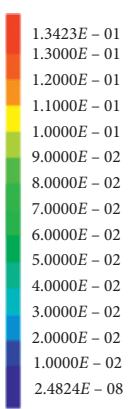

$.4824 E-08$

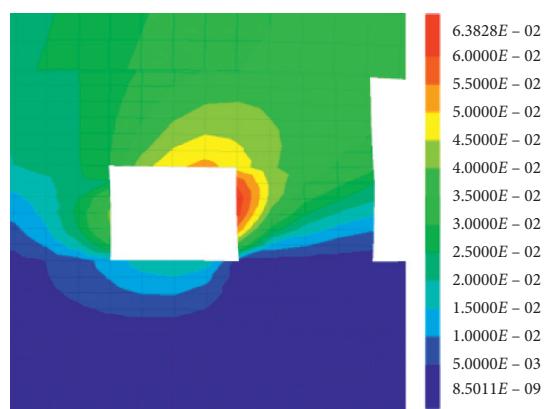

(c)

FiguRe 7: Cloud chart of surrounding rock displacement evolution after excavation of three roadway models. (a) Roadway (1) (unit: m). (b) Roadway (2) (unit: m). (c) Roadway (3) (unit: m).

the stress concentration factor; $H$ is the buried depth of roadway, $m ; \gamma$ is the average bulk density of rock stratum, $\mathrm{kN} / \mathrm{m}^{3} ; C_{0}$ is the cohesion between coal seam and roof rock, $\mathrm{MPa}$; and $P_{x}$ is the support resistance, MPa.

After analysis, the width of the vertical projection plastic zone of the roadway relative to the horizontal plane of the roof is obtained as follows:

$$
L=x_{0}+l+4 .
$$

In (11), $L$ is the width of plastic zone, $m ; x_{0}$ is the width of limit equilibrium zone, $m$; and $l$ is the width of roadway, $m$.

Therefore, in the area of $L=x_{0}+l+4$ under the roof, due to the plastic failure of coal, the supporting force provided by the coal body to the roof decreases, and the stress state of the broken key block is redistributed. The main manifestation is that the mechanical behavior at the hinge joint changes, and, with the S-R instability, the surrounding rock of the roadway produces a lot of deformation.

Before the roadway is excavated, the broken key block is in the limit equilibrium state. It is assumed that the load acting on the key block is decreasing nonuniform load. When the gob-side roadway is excavated under the broken key block, the bearing capacity of the direct roof and coal body will be directly reduced, and the supporting load will be attenuated, which will lead to the secondary subsidence of the broken key block. According to the different subsidence of three groups of model breaking key blocks shown in Figure 12, it is concluded that when the roadway is under the fracture line of key broken block, the attenuation effect on supporting load is the largest. When the roadway is located in the fracture line of the key block, the attenuation effect on the supporting load is moderate. When the roadway is located outside the fracture line of the key block, the attenuation of the supporting load on the broken roof is almost zero. That is, $\Delta q_{1}$ (model (1)) > $\Delta q_{1}($ model (2) $)>\Delta q_{1}$ (model (3) .

According to the first kind of situation, when the roadway is located near the fracture line of the left key block and the middle key block, the pressure relief state generated in the $L$ area will directly act on the hinge joint position. The supporting load $q_{1}$ of the left hinge point of the middle key block decreases sharply, $Q_{C}$ gradually increases and drives the increase of $Q_{A}$ slowly, the extrusion pressure $T$ decreases, the hinge point loses stability, and the right hinge point of the middle key block suffers from the left stress state. The effect of state change is small, and it is still stable. Therefore, the rotation instability of the middle key block takes the hinge point in the direction of the right goaf as the axis, the load generated by the left rotary subsidence directly acts on the $L$ area, which makes the surrounding rock of the roadway produce a large amount of displacement, and the narrow coal pillar and coal body cannot bear the sinking load of the basic roof. Therefore, the side support structure of the coal pillar is required to provide enough support resistance within the effective time to make the middle key block reach the level balance state again.

In the second case, the roadway is all located under the middle key block, and the existence of $L$ area attenuates 


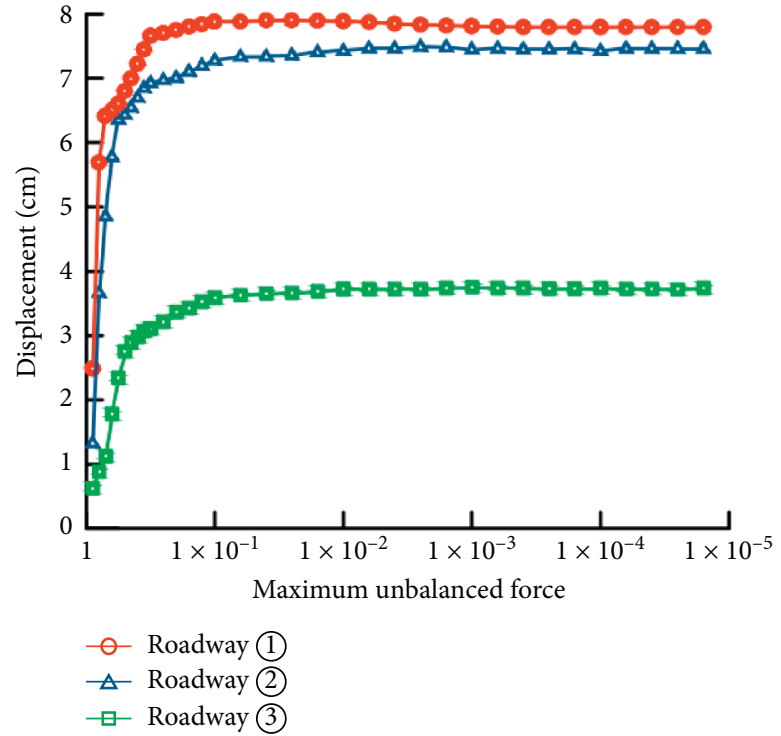

(a)

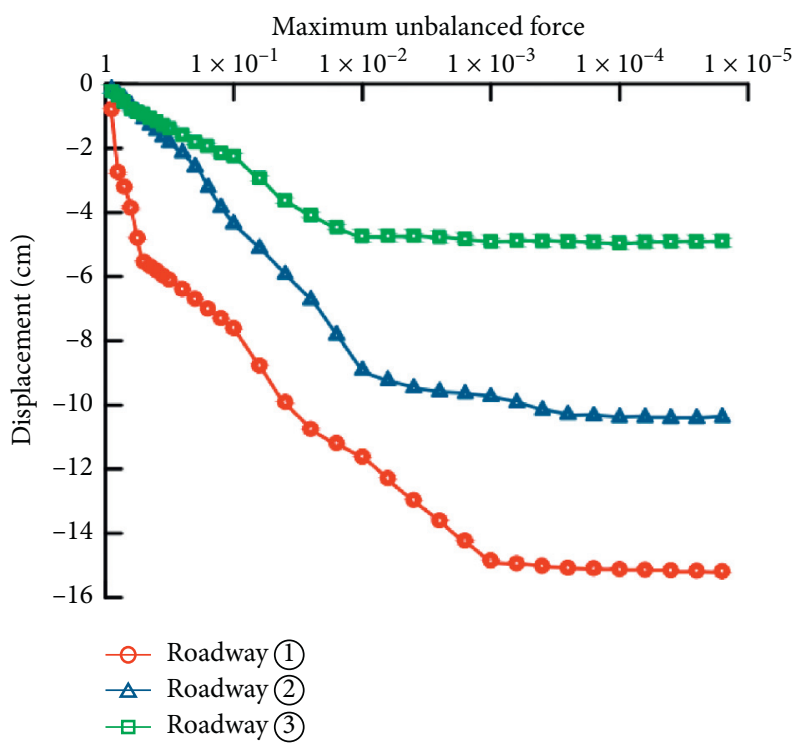

(c)

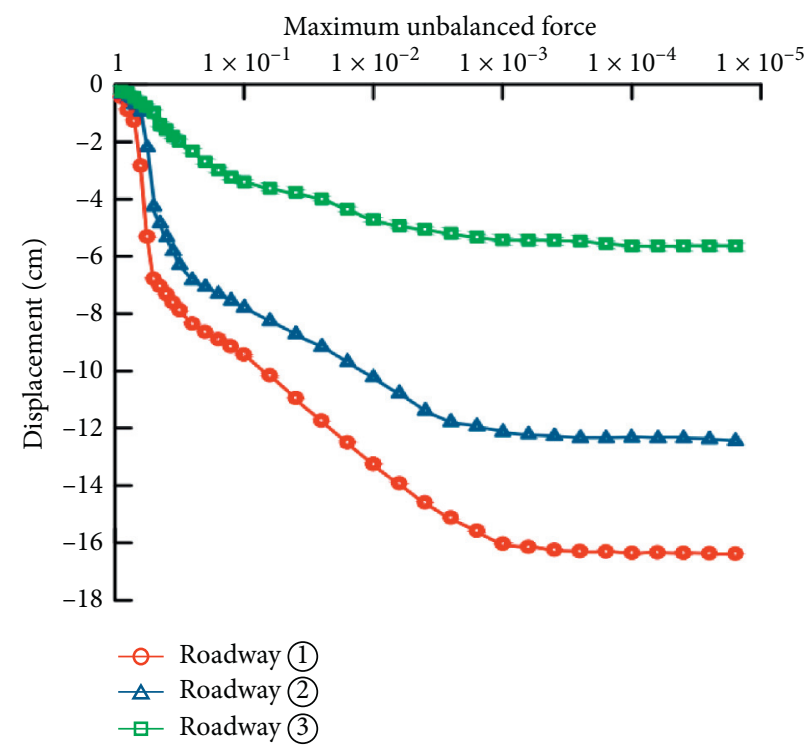

(b)

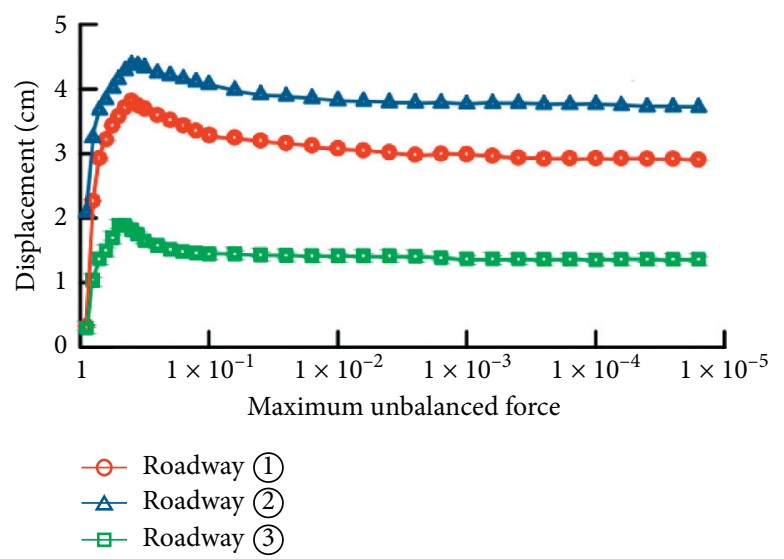

(d)

Figure 8: Displacement curve of measuring points at different positions of roadway. (a) Displacement curve of coal wall side measuring point in roadway. (b) Displacement curve of coal pillar side measuring point in roadway. (c) Displacement curve of roadway roof measuring point. (d) Displacement curve of roadway floor measuring point.

the supporting force. The attenuation center is approximately taken as the center line of the vertical direction of the middle key block. The support load $q_{1}$ decreases, and $Q_{C}$ and $Q_{A}$ increase correspondingly. The middle key block sinks, and the support pressure is applied to the left coal body. Therefore, the angle $\theta$ of the middle key block decreases, the extrusion pressure $T$ decreases, it is difficult for the two hinge joints to maintain the original equilibrium state, and the key block in the middle is sliding and unstable. Due to the pressure produced by its sliding and the subsidence acting on the coal below, the surrounding rock of the roadway will lose its stability and deformation along with a large range of plastic zone. Therefore, in the process of roadway excavation and support, it is necessary to pay attention to the overall supporting measures of surrounding rock to provide a wide range of supporting force to maintain the structural balance.

In the third kind of situation, the roadway is located outside the fault line of the left key block and the middle key block. For the deep soft rock roadway, the strength of the hinge point is low. When the goaf is formed, it will be destroyed due to the large in situ stress, so that the key block in the middle is completely crushed on the gangue pile, and it is difficult to form a triangular support structure. In this space state, the support pressure of coal body is the minimum. The function of $L$ area is mainly in the active range of the left key block; when the support load $q_{1}$ decreases, it is 


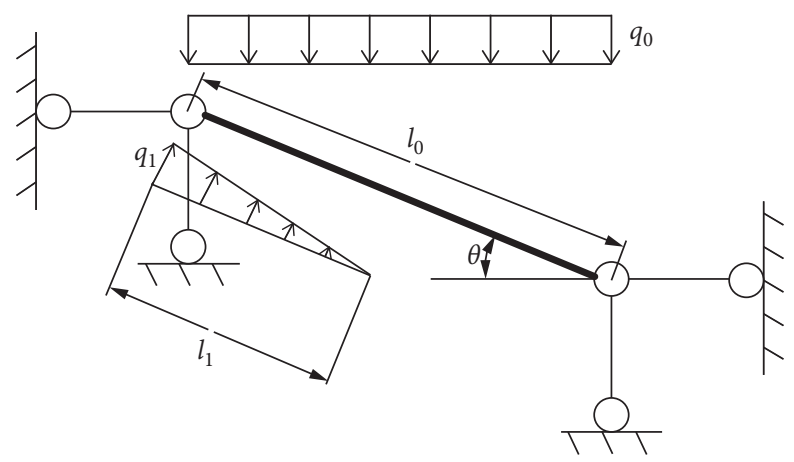

FIGURE 9: Optimization model of "masonry beam."

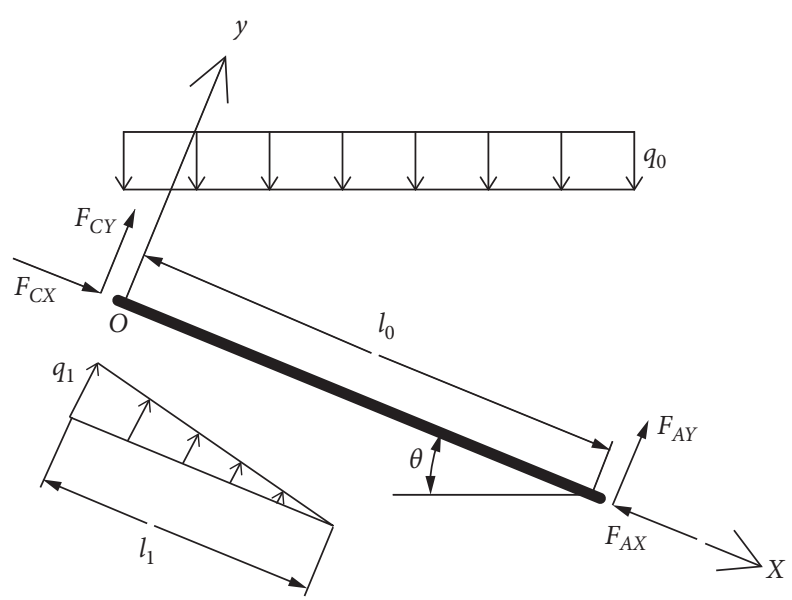

FIGURE 10: Radial force model of "masonry beam."

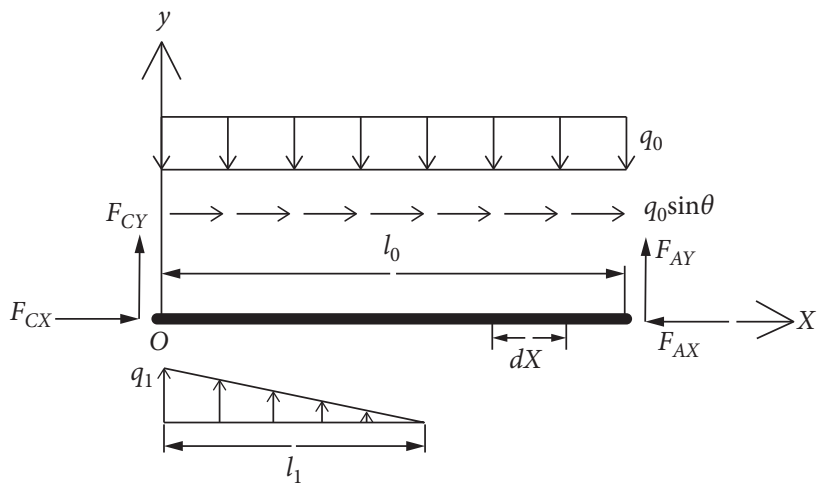

Figure 11: Axial force model of "masonry beam."

only affected by the bearing pressure of left key block, which is not enough to cause S-R instability deformation of the left key block, so the roadway is the most stable in this spatial position.

For the first and second types of structural mechanics models, the state load of "given deformation" caused by breaking key block will directly act on the surrounding rock of roadway, and its size is related to the angle of $\theta$. With the decrease of $\theta$ angle, S-R instability will occur in the middle key block, and the load on coal body will increase gradually. When $\theta=0$, the middle key block will lose the role of friction shear force, the self-gravity and all the load of overlying strata will be borne by the coal below, it will be difficult for the surrounding rock of roadway to maintain stable state, and the support is difficult. Therefore, it is necessary to support the surrounding rock of roadway as soon as possible after the roadway excavation and before the decrease of $\theta$, so as to enhance the stability of surrounding coal, reduce the attenuation amplitude of support load, and restore the balance of large structure within the controllable range of surrounding rock displacement. 


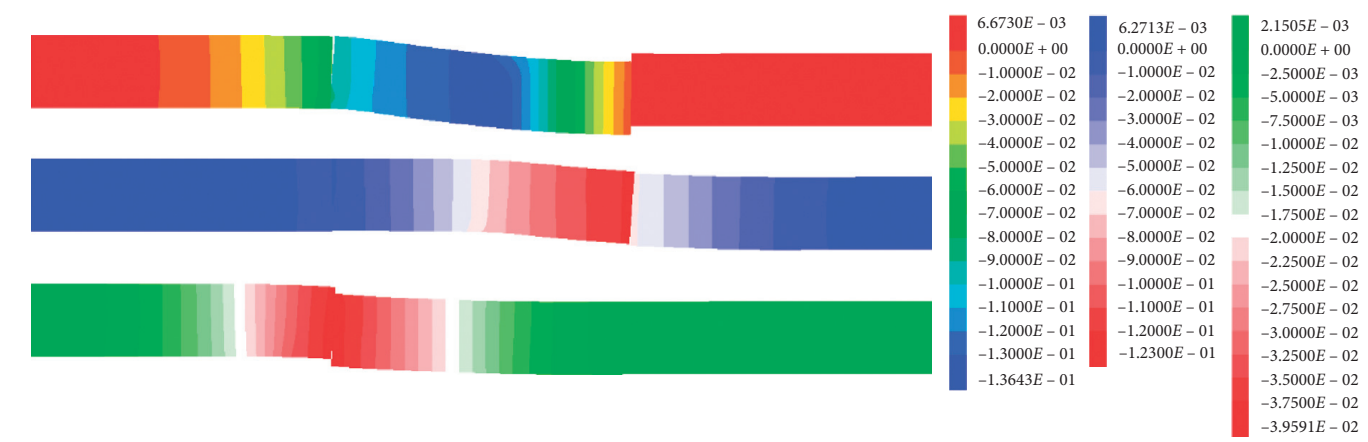

FIGURE 12: Subsidence trend chart of key block broken after roadway excavation based on three groups of models (from top to bottom, model (1), model (2), model (3).

For the third kind of structural mechanics model, the supporting force at the hinge point of the middle key block is mainly provided by the side coal pillar of the goaf, the load of the left key block is mainly borne by the coal mass that has not been mined, the influence of $l$ area on the left key block and the right key block is small, the surrounding rock pressure and displacement of roadway are the minimum, and the structure is most stable.

\section{Conclusions}

(1) The stability of the key block of "masonry beam" is directly related to the compressive strength of rock mass at the hinge point. The roof of deep soft rock roadway is easily affected by the mining disturbance of the upper coal body and the low strength of rock mass itself, resulting in the lower $\sigma_{c}$ of basic roof. If the compressive strength at the hinge point is unable to withstand the extrusion force generated by the rotation of key block, the shear force provided by the hinge point is very weak, and the surrounding rock will gradually sink until the supporting load is enough to maintain the balance of "masonry beam" structure.

(2) The spatial relationship between the roadway and key block can be divided into three types: the roadway is located below the fracture line of key block, the roadway is located inside the fracture line of key block, and the roadway is located outside the fracture line of key block. When the roadway is located below the fracture line of key block, the support pressure at the side of coal pillar is the largest. When the roadway is located inside the fracture line of key block, the support pressure of the coal pillar side is slightly lower than that of the former, but both of them have the risk of single inclined plane shear failure. Moreover, the support pressure range of coal wall side of such roadway is the largest, and the stress superposition area appears in the floor, which leads to a large-scale bottom drum. When the roadway is located outside the fracture line of broken roof, the stress of surrounding rock is the minimum.
(3) The shear forces $Q_{A}$ and $Q_{C}$ at the hinge point of the middle key block are mainly affected by the support load $q_{1}$ and the inclination angle $\theta$, while the extrusion forces $T_{C}$ and $T_{A}$ are only affected by the inclination angle $\theta$. With the decrease of support load $q_{1}$, the shear stresses $Q_{A}$ and $Q_{C}$ increase, and the increase range of $Q_{C}$ is greater than that of $Q_{A}$. However, due to the weak mechanical properties and low strength of the rock, the shear force provided by the rock is far less than the reduction range of the support load $q_{1}$, which makes the broken roof rotate to the horizontal direction, the inclination angle $\theta$ decreases, the extrusion pressures $T_{C}$ and $T_{A}$ produce synchronous attenuation, and the broken roof shows a sinking trend as a whole, for which it is easy to slide and lose stability.

(4) The mechanical evolutionary law of S-R instability of the key block is obtained by analyzing the stress state and deformation characteristics of the key block under three kinds of spatial positions. When the roadway is located below the fracture line of key block, the coal wall and coal pillar cannot provide enough support for the hinge joint, which makes the surrounding rock rotate unstably with the hinge point of the goaf side as the axis. When the roadway is located in the fracture line of key block, the surrounding rock bears the maximum support pressure, and it is easy for the hinge joint on both sides to slide and lose stability when the extrusion pressure decreases. According to these two kinds of roadway layout, the stress superposition caused by concentrated load should be avoided reasonably in effective time, and the surrounding rock of roadway should be reinforced and supported. When the roadway is located outside the fracture line of key block, the middle key block is in the state of complete collapse, the mechanical transmission mechanism of surrounding rock in the vertical direction is weakened, and the surrounding rock is the most stable.

\section{Data Availability}

The data used to support the findings of this study are included within the article. 


\section{Conflicts of Interest}

The authors declare that they have no conflicts of interest regarding the publication of this paper.

\section{Acknowledgments}

This study was financially supported by the National Natural Science Foundation of China (51904266); Key Laboratory of Safety and High-Efficiency Coal Mining, Ministry of Education (Anhui University of Science and Technology) (JYBSYS2018203); High-Level Talent Gathering Project in Hunan Province (2019RS1059); and Hunan Key Laboratory of Geomechanics and Engineering Safety (16GES10).

\section{References}

[1] S. M. Wang, Q. Sun, J. W. Qiao et al., "Geological guarantee of coal green mining," Journal of China Coal Society, vol. 45, no. 01, pp. 8-15, 2020.

[2] L. Yuan, "Scientific problem and countermeasure for precision mining of coal and associated resources," Journal of China Coal Society, vol. 44, no. 01, pp. 1-9, 2019.

[3] M. C. He, H. P. Xie, S. P. Peng et al., "Study on rock mechanics in deep mining engineering," Chinese Journal of Rock Mechanics and Engineering, vol. 24, no. 16, pp. 2803-2813, 2005.

[4] H. P. Xie, "Research framework and anticipated results of deep rock mechanics and mining theory," Advanced Engineering Sciences, vol. 29, no. 02, pp. 1-16, 2017.

[5] H. P. Xie, "Research review of the state key research development program of China:deep rock mechanics and mining theory," Journal of China Coal Society, vol. 44, no. 05, pp. 1283-1305, 2019.

[6] S. R. Xie, Q. Zhang, D. D. Chen et al., "Research and application of asymmetric anchorage deep beam bearing structure model in gob-side entry retaining roof," Journal of Mining \& Safety Engineering, vol. 37, no. 02, pp. 298-310, 2020.

[7] S. R. Xie, H. Pan, D. D. Chen et al., "Stability analysis of integral load-bearing structure of surrounding rock of gobside entry retention with flexible concrete formwork," Tunnelling and Underground Space Technology, vol. 103, pp. 1-11, 2020.

[8] X. Shi, H. Jing, J. Ning, Z. Zhao, and J. Zhu, "Stability control of gob-side entry retaining in fully mechanized caving face based on a compatible deformation model," Computer Modeling in Engineering \& Sciences, vol. 124, no. 1, pp. 315343, 2020.

[9] G. R. Feng, Y. Q. Ren, P. F. Wang et al., "Stress distribution and deformation characteristics of roadside backfill body for gob-side entry of fully-mechanized caving in thick coal seam," Journal of Mining \& Safety Engineering, vol. 36, no. 06, pp. 1109-1119, 2019.

[10] J. G. Kan, J. K. Wu, N. Zhang et al., "Structure stability analysis and control technology of surrounding rock of the secondary gob-side entry retaining," Journal of Mining \& Safety Engineering, vol. 35, no. 05, pp. 877-884, 2018.

[11] H. S. Wang, S. G. Li, X. Z. Zhang et al., "Analysis on stability of narrow coal pillar influenced by main roof fracture structure of gob-side roadway," Coal Science and Technology, vol. 42, no. 02 , pp. 19-22, 2014

[12] Y. Y. Liu, X. M. Song, D. F. Zhu et al., "Dynamic structural mechanical behavior and response characteristics of large key blocks," Rock and Soil Mechanics, vol. 41, no. 03, pp. 10191028, 2020.

[13] S. S. He, S. R. Xie, B. H. Song et al., "Breaking laws and stability analysis of damage main roof in close distance hy-pogynous seams," Journal of China Coal Society, vol. 41, no. 10, pp. 2596-2605, 2016.

[14] D. F. Yang, L. F. Zhang, M. Chai et al., "Study of roof breaking law of fully mechanized top coal caving mining in ultra-thick coal seam based on fracture mechanics," Rock and Soil Mechanics, vol. 37, no. 07, pp. 2033-2039, 2016.

[15] F. L. He, W. R. He, D. D. Chen et al., "First fracture structure characteristics of main roof plate considering elastic-plastic deformation of coal," Journal of China Coal Society, vol. 45, no. 08, pp. 2704-2717, 2020.

[16] J. Zhang, X. H. Duan, and Y. Liu, Research and Application of Surrounding Rock Characteristics and Support Technology of Complex High Stress Soft Rock Roadway, Coal Industry Press, India, 2014, in Chinese.

[17] M. G. Qian, X. X. Miao, and F. L. He, "Analysis of key block in the structure of voussoir beam in longwall mining," Journal of China Coal Society, vol. 19, no. 06, pp. 557-562, 1994.

[18] M. G. Qian and P. W. Shi, Mining Pressure and Strata Control, China University of Mining and Technology Press, Xuzhou, China, 2003, in Chinese.

[19] W. G. Qiao, W. J. Song, Q. B. Meng et al., Failure Mechanism and Support Technology of Deep High Stress Soft Rock Roadway, Wuhan University Press, Wuhan, China, 2017, in Chinese.

[20] C. J. Hou and N. J. Ma, "Coal stress and limit equilibrium zone study on two sides of coal roadway," Journal of China Coal Society, vol. 04, pp. 21-29, 1989, in Chinese. 